\title{
Atribuição de ethos na literatura: análise da narrativa do caso Nardoni
}

\section{Flávia Pereira Dias Menezes}

Doutora em Estudos de Linguagens pelo Centro Federal de Educação Tecnológica de Minas Gerais (CEFET-MG), Brasil orcid.org/0000-0002-5383-3589

\author{
Kelly Fernanda Mayrink Drumond \\ Mestra em Estudos de Linguagens pelo Centro Federal de \\ Educação Tecnológica de Minas Gerais (CEFET-MG), Brasil \\ orcid.org/0000-0001-6320-3831
}

O objetivo deste artigo é analisar as estratégias discursivas utilizadas pelo jornalista Rogério Pagnan ao relatar as trajetórias de vida de Alexandre Nardoni e Anna Carolina Jatobá, condenados pela morte da menina Isabella Nardoni em 2008. A proposta é mostrar como foi construído o discurso sobre o crime e sobre os seus personagens pelo autor em sua obra 0 pior dos crimes: a história do assassinato de Isabella Nardoni, divulgada dez anos após o crime que ganhou repercussão nacional. Buscamos averiguar quais as vozes evocadas no discurso e como a narrativa contribui para a (des)construção de imagens dos atores sociais. Para tanto, utilizamos a dimensão discursiva-argumentativa do ethos, principalmente a partir dos postulados de Maingueneau (2008) e Charaudeau (2005), a fim de verificar os possíveis efeitos de sentido gerados a partir da narrativa.

Palavras-chave: Isabella Nardoni. Discurso. Ethos. Narrativa.

\section{Atribución del ethos en la literatura: análisis la narrativa del caso Nardoni}

El objetivo de este artículo es analizar las estrategias discursivas empleadas por el periodista Rogério Pagnan al relatar las trayectorias de vida de Alexandre Nardoni y Anna Carolina Jatobá, condenada por la muerte de la niña Isabella Nardoni el 29 de marzo de 2008. La propuesta es mostrar cómo se construyó el discurso del autor sobre el crimen y sus personajes en su obra El peor de los crímenes: la historia del asesinato de Isabella Nardoni, publicada diez años después del crimen que ganó repercusión nacional. Buscamos conocer qué voces se evocan en el discurso y cómo la narrativa contribuye a la (des) construcción de imágenes por parte de los actores sociales. Por tanto, utilizamos la dimensión discursivoargumentativa del ethos, principalmente a partir de los postulados de Maingueneau (2008) y Charaudeau (2005), con el fin de verificar los posibles efectos de sentido generados a partir de la narrativa.

Palabras clave: Isabella Nardoni. Discurso. Carácter distintivo. Narrativa.

\section{Attribution of ethos in literature: analysis the narrative of the Nardoni case}

The aim of this article is to analyze the discursive strategies used by journalist Rogério Pagnan when reporting the life trajectories of Alexandre Nardoni and Anna Carolina Jatobá, convicted of the death of the girl Isabella Nardoni on March 29,2008 . The proposal is to show how the authorial discourse about the crime and its characters was constructed in his work The worst of crimes: the story of the murder of Isabella Nardoni, published ten years after the crime that gained national repercussion. We aim at discerning which voices are evoked in the discourse and how the narrative contributes to the (de)construction of social actors' images. To do so, we deploy the discursive-argumentative dimension of ethos, mainly from the postulates of Maingueneau (2008) and Charaudeau (2005), in order to verify the possible meaning effects generated from the narrative.

Keywords: Isabella Nardoni. Discourse. Ethos. Narrative. 


\section{Introdução}

O dia 29 de março de 2008 ficou marcado na história brasileira como um dos crimes de maior repercussão nacional: o caso da menina Isabella Nardoni que foi arremessada do sexto andar do edifício London, em São Paulo. Esse acontecimento transformou-se em um dos assuntos mais comentados nas conversas cotidianas e veiculado compulsivamente pela mídia, já que os principais suspeitos pela morte da menina de 5 anos eram o pai, Alexandre Nardoni, e a madrasta, Anna Carolina Jatobá. $\mathrm{O}$ acontecimento era instigante, porque durante todo o processo de investigação e julgamento, o casal não confessou o crime e alegava uma terceira pessoa, um ladrão, na cena do crime, e, dessa forma, deixava dúvidas quanto à autoria e à motivação para 0 assassinato.

Ao completar dez anos do crime, em 2018, o repórter policial Rogério Pagnan publicou o livro O pior dos crimes: a história do assassinato de Isabella Nardoni, que narra as trajetórias de vida do casal e de suas famílias, além de apresentar dados sobre o dia do crime, os rumores da investigação e de levantar dúvidas se havia elementos suficientes para a condenação do casal.

Com base na obra de Pagnan (2018), o objetivo deste artigo é analisar as estratégias discursivas utilizadas pelo jornalista ao relembrar as nuances do crime e de seus personagens engendrados na trama. Para tanto, será examinada a dimensão argumentativa do discurso, o ethos - ou seja, como se deu a projeção de imagens dos sujeitos arrolados na narrativa, e a construção da narrativa que aborda os dados técnicocientíficos embasados pela perícia responsável pelo caso, conta minúcias da infância do casal e de sua família e, principalmente, as informações que colocam em xeque a autoria do crime.

Nesse sentido, a proposta do artigo é examinar a composição da obra literária. Em um primeiro momento, vamos abordar os conceitos de narrativas de vida e os aspectos que envolvem a narração de uma história biográfica, partindo dos pressupostos teóricos de Machado (2016), Dosse (2009) e Bertaux (1994). Trata-se de explorar a dimensão argumentativa de um discurso que possui características de escrita biográfica na qual fatos reais e ficcionais estão imbricados.

$\mathrm{Na}$ sequência, apresentaremos uma relação entre os conceitos teóricos e a dinâmica da narrativa do caso Nardoni, verificando os efeitos de sentido construídos ao atribuir traços de caráter dos personagens por meio do ethos, principalmente a partir dos postulados de Maingueneau (2008) e Charaudeau (2005). 


\section{Narrativas de vida}

O processo de contar a vida de outra pessoa é estabelecido quando o sujeitoenunciador seleciona os fatos que pretende mostrar e esclarecer sobre o sujeito biografado e, ao mesmo tempo, de forma consciente ou não, silencia, omite alguns dados e informações (CARVALHO, 2016).

A narrativa surge justamente do "[...] equilíbrio feito pelo sujeito-narrador entre seu testemunho factual incrementado por fatores ficcionais. Estes últimos tentam preencher lacunas da própria fala ou da escrita. Seja como for, memória e a imaginação andam sempre de mão dada" (MACHADO, 2016, p. 80, grifo no original). Dosse (2009) destaca, justamente, essa tensão constitutiva do gênero biografia, por estar "navegando" entre o factual e a vontade estética. Ele considera a biografia um gênero híbrido, ou seja, ela se situa numa tensão da vontade de reproduzir um vivido real passado por meio do resgate das vivências pela memória e o polo imaginativo do biógrafo, que depende da dimensão histórica e da dimensão ficcional.

Contudo, Machado (2016) e Dosse (2009) parecem querer mostrar como as narrativas são construções discursivas estruturadas na tensão entre um "desejo de verdade", "desejo de referencialidade", de todo impossível e ficcionalidade.

Portanto, ao narrar a sua própria história ou de outra pessoa, o sujeito recorre à memória, lembranças de experiências e acontecimentos vividos e, assim, estrutura a vida e constrói sua trajetória pela atuação na sociedade e no relacionamento com os outros. Barthes (2013) nos lembra de que são inumeráveis as narrativas do mundo, elas começam com a própria história da humanidade e são sustentadas pela linguagem oral ou escrita, pela imagem, pelo gesto e podem estar "[...] no mito, na lenda, na fábula, no conto, na novela, na epopeia, na história, no drama, na comédia, na pantomima, na pintura [...], no vitral, no cinema, nas histórias em quadrinhos, no fait divers, na conversação" (2013, p. 19).

A narrativa, para Barthes (2013, p. 57), é "[...] uma língua fortemente sintética, fundada essencialmente sobre uma sintaxe de encaixamento e de desenvolvimento: cada ponto da narrativa irradia em muitas direções ao mesmo tempo". A partir dessa conceituação, o autor dá um exemplo de James Bond ao pedir um uísque no avião, sendo que o uísque tem valor polissêmico, por ser um índice, podendo remeter à modernidade, riqueza e, como unidade funcional, o pedido do uísque percorre a etapa da consumação, espera, partida etc. "[...] para encontrar a sua significação final: a unidade é 'tomada' por toda a narrativa, mas também a narrativa não 'subsiste' a não ser pela distorção e irradiação de suas unidades" (2013, p. 57).

Genette (2013) aponta a definição de narrativa no domínio da expressão literária, que é "[...] a representação de um acontecimento ou de uma série de acontecimentos, 
reais ou fictícios, por meio da linguagem e, mais particularmente, da linguagem escrita" (GENETTE, 2013, p. 265). Porém, o autor nos chama a atenção para essa definição positiva e corrente, pois apaga as condições de sua existência. Ele acredita que definir de forma positiva a narrativa é "[...] acreditar, talvez perigosamente, na ideia ou no sentimento de que a narrativa é evidente, de que nada é mais natural do que contar uma história ou arrumar um conjunto de ações em um mito, um conto, uma epopeia, um romance" (GENETTE, 2013, p. 265, grifo no original).

Nesse contexto das narrativas, Genette (2013) aborda a diferença de objetividade da narrativa e subjetividade do discurso definidas por critérios de ordem propriamente linguística. Enquanto a subjetividade é marcada, no discurso, pela presença explícita, ou não, do "eu", mas um "eu" que não se define como a pessoa que mantém o discurso, a objetividade da narrativa, para o autor, é a ausência de toda referência ao narrador.

Seguindo com as definições de narrativas de vida, relevante trazer as contribuições de Bertaux ${ }^{1}$ (1994) que pertence ao campo da Sociologia. Assim, mostramos a interdisciplinaridade com a qual temos trabalhado, principalmente, a partir dos estudos de Machado (2016). A narrativa de vida, para Bertaux (1994), é como um discurso narrativo que se empenha em contar uma história "real", mas ele sinaliza que é diferente da autobiografia por se derivar de uma relação dialógica entre pesquisador e informante, processo orientado para fazer emergir descrições de experiências pertinentes ao objeto de estudo.

A estrutura diacrônica de eventos biográficos, segundo Bertaux (1994), faz-se em torno de um núcleo central estável em torno do qual se desenvolve, trata-se da construção de um enredo. Podemos perceber que duas narrativas sobre os mesmos fatos tendem a salientar aspectos distintos, pontuam, enaltecem pontos distintos. $O$ núcleo central possui uma estrutura diacrônica. Bertaux (1994) destaca que o sujeito guarda os eventos mais marcantes segundo a ordem temporal em que os viveu. Entretanto, não significa que o sujeito estabelecerá sua narrativa de forma linear, uma vez que a narrativa de vida "vai e vem", como toda narrativa espontânea. Assim, somente no trabalho analítico se pode estabelecer uma estrutura diacrônica, que representa uma objetividade discursiva.

Segundo Bertaux (1994), no esforço do sujeito em contar uma história realmente vivida, pode-se distinguir três ordens de realidade: histórico-empírica, psíquicosemântica e realidade discursiva. A histórico-empírica trata-se da história realmente vivida, que o autor prefere designar pelo termo "percurso biográfico", e não "trajetória"; o percurso inclui não somente a sucessão de situações objetivas do sujeito, mas a maneira pela qual ele as viveu, percebeu, avaliou e agiu. A realidade psíquico-semântica

\footnotetext{
${ }^{1}$ A tradução do texto de Bertaux (1994), utilizada neste artigo, foi feita pelo professor do Programa de Pós-Graduação em Estudos de Linguagens do CEFET-MG, Cláudio Humberto Lessa.
} 
é resultante da totalização subjetiva que o sujeito faz de suas experiências, o que o sujeito sabe e pensa retrospectivamente de seu percurso. Já a realidade discursiva se refere à narrativa em si, resultante da relação dialógica da entrevista, correspondente ao que o sujeito quis dizer do que ele sabe ou crê saber e pensa de seu percurso.

Há então entre o percurso biográfico e a narrativa que dele se faz, um nível intermediário, o da totalização subjetiva (sempre em evolução) da experiência vivida. Ela constitui o conjunto de materiais mentais a partir dos quais o sujeito busca produzir uma narrativa. Ela é feita de lembranças, mas também de pontos de vista, de reflexões e de avaliações retrospectivas (BERTAUX, 1994, p. 68).

É preciso considerar que uma biografia, para Bertaux (1994), resulta de um ponto de vista que ecoa uma época e um grupo social. Trata-se de uma mobilização de capacidades subjetivas. O mesmo ocorre na autobiografia, porém, nessa modalidade, o sujeito narra sua própria vida, do interior e a considera retrospectivamente.

No final desse breve détour, compreende-se melhor o que constitui uma narrativa de vida: uma improvisação sem notas (sem recursos a arquivos escritos), fundando-se na rememoração dos eventos principais tais como foram vividos, memorizados e totalizados, esforçando-se para discernir os encadeamentos (BERTAUX, 1994, p. 70).

Concluindo essa parte, podemos considerar que os autores de diversos domínios utilizados para conceituarmos narrativa de vida apontam para o caráter linguístico e discursivo das narrativas.

\section{A noção de Ethos}

$\mathrm{Na}$ encenação de um ato de linguagem, o sujeito-enunciador projeta imagens de si, imagens do outro e imagens do mundo. As imagens de si podem ser marcadas por estratégias que envolvem um engajamento explícito, ou seja, o locutor revela sua própria posição quanto aquilo que diz; ou de um apagamento, ao utilizar de formas impessoais por meio de asserções ou discurso relatado.

Quanto à imagem do outro, o locutor implica o interlocutor em seu ato de enunciação ao deixar marcas de segunda pessoa, por exemplo. O mundo diz respeito aos eventos e interpretações, lugares que existem multiplicidade de discursos e pontos de vista.

Nessas projeções de imagens, temos o ethos. Ao lado do logos e do pathos, constitui as três dimensões argumentativas do discurso. Essa é a concepção do filósofo grego Aristóteles (384-322 a.C.), que divide os meios discursivos que influenciam o auditório nessas três categorias. O primeiro e o terceiro conceitos são pertencentes ao domínio da emoção, sendo o ethos voltado para o orador e o pathos para o auditório. $O$ 
segundo, por sua vez, pertencente ao domínio da razão, tornando possível o convencimento (CHARAUDEAU, 2008).

Estas três provas - ethos, logos e pathos - caracterizam-se como qualidades que o orador deve demonstrar para assegurar a eficácia de um discurso, e se dão, basicamente, por três construções: as que residem no caráter moral do orador, as baseadas na disposição do ouvinte e, por último, as que se fundamentam no próprio discurso. Dessa maneira, segundo a teorização de Aristóteles, a persuasão está garantida quando se atinge as três esferas: persuade-se pelo caráter (ethos), persuadese pela disposição dos ouvintes quando estes sentem emoção (pathos) e, enfim, pelo discurso em si (logos) (ARISTÓTELES, 1998, [s.p.]).

Para elucidar essa questão, Maingueneau (2008, p. 14) retoma a fórmula de Gibert (século XVIII), que resume o triângulo da retórica antiga em: "[...] instrui-se pelos argumentos; comove-se pelas paixões; insinua-se pelas condutas", em que os "argumentos" correspondem ao logos, as "paixões" ao pathos e as "condutas" ao ethos.

Especificamente no que concerne à noção retórica do ethos, Maingueneau (2008, p. 13) elucida que "[...] a prova pelo ethos consiste em causar boa impressão pela forma como se constrói o discurso, a dar uma imagem de si capaz de convencer o auditório, ganhando sua confiança". Para esse fim, segundo o autor, o orador pode se valer de três qualidades fundamentais: a phronesis, ou prudência, a aretè, ou virtude, e a eunoia, ou benevolência.

No que diz respeito a outro ponto de vista aristotélico, Maingueneau (2008, p. 16) explica que o ethos se elabora por meio de uma percepção complexa, "[...] mobilizadora da afetividade do intérprete, que tira suas informações do material linguístico e do ambiente". Segundo o autor, os índices sobre os quais se apoia o intérprete na elaboração do ethos vão "[...] desde a escolha do registro da língua e das palavras até o planejamento textual, passando pelo ritmo e a modulação" (2008, p. 16).

Junto com um convite para que se alargue o alcance do conceito de ethos, Maingueneau (2008) apresenta também a noção de ethos coletivo, que aqui merece um ponto de destaque. Segundo o autor, essa é uma dimensão que associa o sujeito às características do grupo social ao qual ele pertence, relacionando aos hábitos partilhados por membros de uma comunidade.

É muito razoável supor que os diferentes comportamentos de uma mesma comunidade obedecem a uma certa coerência profunda e, então, esperar que sua descrição sistemática permita distinguir o "perfil comunicativo", ou ethos, dessa comunidade (ou seja, a sua maneira de se comportar e de se apresentar nas interações - mais ou menos caloroso ou frio, próximo ou distante, modesto ou imodesto, "sem 
constrangimentos" ou respeitoso do território alheio, suscetível ou indiferente à ofensa etc.) (MAINGUENEAU, 2008, p. 16).

Para Charaudeau (2005, p. 117), o ethos coletivo "[...] corresponde a uma visão global, mas à diferença do ethos singular ele é construído apenas pela atribuição apriorística de uma identidade que emana de uma opinião coletiva em relação a um outro grupo".

Conceitos postos, os imaginários sociodiscursivos podem nos levar a pensar, por exemplo, em um ethos coletivo para pais, mães e madrastas. Nesse caso específico, temos configuradas as percepções de um provedor-educador, uma mulher honrosa e abnegada e, na construção imaginária de uma madrasta, o estigma de uma vilã má. E é a partir dessa abordagem que serão avaliados traços de caráter (ethos) analisados.

Aqui, chamamos a atenção para o fato de que, em nosso estudo, os sujeitos não falam por si. Apesar da noção central de ethos estar associada à imagem que o orador pretende dar de si mesmo, não vamos analisar a corporalidade do casal condenado, mas a construção da imagem feita pelo autor jornalista, e, a partir de tais enunciados, identificar os possíveis ethé associados a eles.

\section{Análise da obra: relação entre os conceitos teóricos e a dinâmica da narrativa do caso Nardoni}

O corpus de análise deste artigo é O pior dos crimes: a história do assassinato de Isabella Nardoni, publicado pela Editora Record. A obra, de autoria do jornalista Rogério Pagnan, é vinculada ao gênero de Crimes Reais e conta com 336 páginas divididas em 35 capítulos. Pagnan é formado pela Universidade de Franca e repórter da Folha de S.Paulo desde 2000. Especialista em segurança pública, escreve sobre investigações policiais e grandes júris. É ganhador do Grande Prêmio Folha de Reportagem de 2012 e do Prêmio Latino-americano de Jornalismo de Investigação de 2017, organizado pelo Instituto de Prensa y Sociedad (IPYS) e pela ONG Transparência Internacional.

No preâmbulo do livro, intitulado "Foram eles (?)", o jornalista já sinaliza para o leitor uma questão que requer uma reflexão sobre a culpabilidade dos condenados pelo assassinato de Isabella Nardoni. Assim, permite-nos considerar a dúvida sobre a autoria do crime, ou seja, se realmente seriam o pai Alexandre e a madrasta Anna Carolina os verdadeiros assassinos. Nessa seção, o autor narra uma história polêmica de assassinato ocorrido em um camping na Austrália nos anos de 1980. Uma criança de 9 semanas de vida estava dormindo em uma barraca e foi levada por um dingo ${ }^{2}$, conforme suspeita da mãe da criança. A partir da investigação da polícia, foram encontradas

\footnotetext{
2 Espécie de cão selvagem, considerado o maior predador terrestre da Austrália. Classificação taxonômica inserida na espécie Canis Lupus.
} 
pegadas do animal e o macacãozinho ensanguentado do bebê em local distante da barraca em que se encontrara antes do desaparecimento, porém os restos mortais da criança nunca foram localizados. Diante desse cenário, surgiram as suspeitas de que os pais fossem os autores do crime. Em um primeiro momento foi considerado pela Suprema Corte que não havia crime, porém devido ao clamor popular, os pais foram condenados dois anos após a morte do bebê. A mãe foi condenada à prisão perpétua $\mathrm{e}$ o pai, acusado como cúmplice do crime, foi condenado a dezoito meses de cadeia.

A história contada pelo jornalista serve como gancho para a analogia com o caso Nardoni, acontecimento acompanhado pelo repórter policial que participou do julgamento do casal como testemunha em 2010 por ter redigido uma matéria jornalística, dois anos antes do julgamento, com o pedreiro Gabriel que falara de um portão arrombado em um prédio ao fundo do edifício London, onde acontecera o crime. Segundo Pagnan (2018), a história da família australiana, que virou filme, apresentou semelhanças com o caso de Isabella:

a) as pessoas consideraram as histórias inverossímeis e elegeram as mulheres como as principais suspeitas, ambas tidas como 'esquisitas'; b) as condenações foram baseadas principalmente em provas periciais, vistas como irrefutáveis, ainda que frágeis e lideradas por peritos polêmicos; c) os principais indícios eram marcas de roupas que indicavam a dinâmica do crime e, ainda, supostas manchas de sangue encontradas no interior do veículo da família; d) os promotores usavam a mesma expressão para definir a história dos réus: 'fantasiosa'; e) as Promotorias não conseguiram apontar motivação dos assassinatos; $\mathrm{e}$, por fim, os dois casais se declararam inocentes todo o tempo (PAGNAN, 2018, p. 14).

A partir desses tópicos pontuados pelo autor, podemos traçar também a dinâmica da narrativa. Quanto à verossimilhança dos fatos narrados pelo casal e a participação da mulher tida como 'esquisita'; o narrador tenta, implicitamente, mostrar para o leitor que, pelos horários da chegada da família ao edifício e a dinâmica no dia do crime, havia a possibilidade de existir uma terceira pessoa na cena do crime, conforme álibi explorado incessante pela dupla. E foi esse ponto, que concerne aos horários da chegada ao edifício onde moravam e o assassinato da menina, argumentado pela promotoria no julgamento, que levou a condenação do casal.

Sobre a madrasta, que no imaginário dos contos infantis é tida como uma mulher má, sem coração e que tenta, de toda forma, livrar-se da enteada, o jornalista busca "humanizar" Anna Carolina Jatobá e mostrar o bom relacionamento que tinha com a menina Isabella. As tentativas vão desde o relato da disponibilidade da madrasta em buscar Isabella para levá-la para a sua casa, o cuidado da enteada nas ruas ao andar de mãos dadas com ela, deixando o próprio filho para trás no supermercado, até a narração de um quarto digno de uma princesa separado e decorado especialmente para a menina em sua casa. 
A respeito das condenações que, segundo o narrador, foram baseadas em provas periciais irrefutáveis, frágeis e lideradas por peritos polêmicos, a narrativa busca mostrar que não havia provas contundentes para a prisão, conforme o trecho a seguir: "Tanto Alexandre quanto Anna, apesar das 'provas' apresentadas pelos policiais, mantiveram a versão da inocência. Irredutivelmente" (PAGNAN, 2018, p. 166).

O delegado Aldo Galiano Júnior confirmaria aos jornalistas no final daquela tarde (antes dos depoimentos da madrasta) que ambos estavam indiciados. Entre os principais motivos, segundo diriam as manchetes, estavam a mancha de vômito na camisa do pai, o comportamento evasivo dos suspeitos, que para quase tudo diziam 'não sei explicar', e o fato de Anna ter chamado o marido de 'tartaruga'" (PAGNAN, 2018, p. 166).

Ao marcar o termo "provas" com a utilização das aspas pelo enunciador, interpretamos como uma tentativa de colocar em dúvida sobre a existência e autenticidade das provas coletadas pela perícia criminal para imputação e condenação do casal. Para ratificar essa dúvida gerada quanto às provas, a narrativa apresenta 0 médico Laércio de Oliveira do Instituto Médico Legal, 33 anos de profissão. Mesmo sendo considerado na narrativa como um profissional honesto e competente, questionase a credibilidade dos resultados da perícia técnica encontrados nos laudos. O autor evocou outras vozes no discurso para contradizer os resultados e apontou a opinião de outros médicos sobre a avaliação do caso Nardoni, especialmente quando foi detectada a asfixia na vítima. O cirurgião André Morrone que estudou os laudos por conta própria diz: "'Sobre a asfixia, eu não vejo elementos. Não vou olhar o resto das provas criminais. Mas, olhando a parte médico-legal, eu não vejo evidência disso. No politrauma, sem dúvida"' (PAGNAN, 2018, p. 191).

Além de inferir que houve várias incongruências por parte da perícia e associar a investigação com um grande espetáculo oriundo de ficção científica, as críticas também se deram em relação à conduta do promotor do caso que usou a expressão "fantasiosa" para definir a história dos réus:

Sobre o caso Nardoni, Cembranelli deu a primeira entrevista horas após assumir o caso, antes mesmo de ter contato com os suspeitos ou testemunhas. Montou toda a sua conviç̧ão em uma rápida leitura das 136 páginas do inquérito para decretar que não acreditava na versão contada por Alexandre e Anna. 'A versão do casal é "fantasiosa", disse ele à jornalista Laura Diniz, do Estadão (PAGNAN, 2018, p. 245).

Está no âmbito do subentendido que o promotor montou um discurso condenatório dos suspeitos com o intuito de ter notoriedade na mídia já que não tinha se informado adequadamente sobre o processo e já foi logo condenando os suspeitos. Pagnan (2018) atribui um ethos midiático a Cembranelli que gostava de aparecer até mesmo em 
programas de entretenimento da televisão, agindo como celebridade que gosta de holofotes, com a utilização de frases de efeito.

Nesse sentido, o autor aponta como indicativos da inocência do casal a coesão nos depoimentos e a falta de confissão de Alexandre e Anna Carolina. "Os dois não confessariam. Preferiram enfrentar um júri diante do qual, poucos duvidavam, ambos tinham pouquíssimas chances de serem inocentados. Por quê?" (PAGNAN, 2018, p. 226).

O primeiro capítulo "London" conta toda a dinâmica do momento em que ocorreu a queda da criança, desde a ligação de Alexandre Nardoni para a emergência da Polícia Militar de São Paulo até os movimentos dos vizinhos diante da situação. O seu Lúcio, um dos primeiros moradores do edifício, é inserido na narrativa como uma pessoa que não ajudou na prestação de socorro à vítima. Percebemos uma atribuição de ethos de passividade, como observamos no trecho a seguir: "o morador perderia o cargo de síndico na eleição realizada naquele mês de março de 2008, quando o London já tinha cerca de vinte apartamentos ocupados, mas ele ainda mantinha o status de mandachuva" (PAGNAN, 2018, p. 21).

O capítulo "Socorro em vão" narra a chegada ao edifício London da mãe de Isabella, Ana Carolina de Oliveira, bem como dos familiares de Alexandre e a notícia da morte da menina de cinco anos. No capítulo, o destaque é o carinho que os pais de Alexandre tinham com a neta Isabella, principalmente a avó, conforme observamos no trecho a seguir: "Não há quem duvide, em qualquer das famílias, de que Cida tinha um amor incondicional por Isabella. Ninguém, portanto, seria capaz de impedir que a avó fosse com o marido até o London para ver o que tinha acontecido com seu 'botão de rosa', maneira como gostava de chamar a neta (PAGNAN, 2018, p. 31).

Além da demonstração de quanto a menina era bem querida e amada no seio da família Nardoni, a chegada da mãe ao local do crime antes dos avós por parte de pai causou espanto em Antônio, pai de Alexandre Nardoni, como percebemos no trecho: "Tempos depois, seu Antônio questionaria como seria possível Carol ter chegado tão rápido ao London, antes mesmo que ele" (PAGNAN, 2018, p. 32).

Interpretamos a fala de Antônio Nardoni como uma suspeita de que a mãe de Isabella poderia estar de alguma forma envolvida com o crime. Durante a narrativa, percebemos também uma tentativa de desqualificar o caráter, a conduta e a honra de Ana Carolina de Oliveira ao caracterizá-la como uma mulher impulsiva, que não queria a filha devido à suposta tentativa de aborto, uma pessoa que gostava muito de baladas e de gênio difícil. A mãe de Ana Carolina também não foi poupada das críticas, como podemos observar no trecho a seguir: "A principal responsável pelo clima pouco agradável, diria o namorado, era a mãe da moça, dona Rosa, que tinha uma personalidade forte e, poucos discordavam, conseguia impor a vontade dela sobre a 
dos filhos e até mesmo sobre a do marido, José Arcanjo" (PAGNAN, 2018, p. 61). A atribuição do ethos intransigente a Ana Carolina pode ser observado no trecho a seguir: "Alexandre não conseguia emplacar o nome Pamela na filha nem convencer a namorada a marcar a cesárea para o dia 17 de abril, aniversário da mãe dele, o que representaria uma homenagem a dona Cida" (PAGNAN, 2018, p. 63).

O autor traz para a cena discursiva a ex-namorada de Alexandre, Patrícia, uma vizinha que teve um relacionamento amoroso bem profundo, com direito a declarações, que corrobora com a personalidade e gênio difíceis de Ana Carolina de Oliveira, além da impulsividade.

Eu não podia visitá-los [os Nardoni], continuou Patrícia. Quando eu ia na casa da Cida, na época em que a Carol estava com Alexandre, eu tinha que ir escondida. Tinha que ir escondida porque ela não aceitava que eu frequentasse aquela casa. Ela fazia um inferno na família se eu fosse. Uma vez ela jogou o carro em cima de mim. Quando viu que era eu, jogou em cima. Ela sempre foi doidinha. Meio pá virada. Era bagunceira, gostava de sair, curtir. Namorar bastante. Não que isso seja problema. Mas ela sempre foi encrenqueirinha. Não é aquela imagem de santa que ela passa', resume a moça (PAGNAN, 2108, p. 64).

O autor atribui um ethos de prepotência e de insensibilidade da mãe de Isabella, uma mulher que não aceita opiniões e que sempre parte para o embate e discussões. Quando ela entrou na justiça requerendo pensão alimentícia para a filha, o autor mostra que foi uma desavença para os Nardoni que davam de tudo para a menina. "Se a mãe de Isabella tinha mesmo alguma intenção de magoar os Nardoni, conseguiu" (PAGNAN, 2018, p. 75). Essa projeção de imagem é totalmente contrária ao descrever Anna Carolina Jatobá: uma menina que não deu preocupações para os pais, caseira e criada como uma princesa pelos pais. O autor sinaliza, assim, dois extremos, duas personalidades bem diferentes e conflitantes.

Durante a narrativa, o autor questiona ainda o trabalho da Polícia Militar, dos peritos criminais e faz críticas sobre a estrutura das polícias militar e civil no Brasil. Questiona a credibilidade de alguns profissionais, como no caso da delegada da Polícia Civil, Renata Pontes: "Embora estivesse realmente ido ao local do crime de Suzane e citasse o episódio em seu currículo profissional, Renata não comandou as investigações nem chegou a ficar famosa com elas" (PAGNAN, 2018, p. 44).

Sobre Rosângela Monteiro, a principal perita do caso, o autor coloca em dúvida até mesmo o diploma. Segundo Pagnan (2018), a perita apresentava-se em palestras como mestre e doutora pela PUC São Paulo e, de acordo com ele, a Instituição não confirma a informação, aferindo a ela um ethos de conduta duvidosa. Além do profissional, o autor apresentou algumas lacunas na investigação, atribuindo implicitamente a incompetência da perita, como, por exemplo, a falta de registro 
fotográfico das manchas de sangue visíveis e também o não envio ao laboratório do suposto sangue detectado no chão pelo reagente.

Se por um lado a narrativa coloca em xeque a competência e a credibilidade dos profissionais responsáveis pela investigação do caso, por outro, parece-nos que houve interesse em enfatizar a boa índole da família Nardoni, a começar por referir ao pai de Alexandre, Antônio Nardoni de Toninho, uma maneira familiar e íntima de se dirigir a uma pessoa. Dessa forma, o capítulo 4, "Pontes de Roma" é dedicado ao início humilde da família de Alexandre. Durante as investigações, Alexandre foi taxado pela mídia como um rapaz dependente financeiramente do pai e imaturo. Interpretamos como uma tentativa do autor em desfazer essa imagem de um rapaz mimado e nascido em berço de ouro ao trazer uma narrativa do início do casamento de dificuldades financeiras de Antônio Nardoni e Maria Aparecida e uma invasão de um maluco com uma faca quando Maria Aparecida estava grávida de Alexandre. Os detalhes da vida simples foram resgatados na narrativa, o pouco recurso para compras de supermercado, a boa convivência com os vizinhos e a ascensão financeira de "Toninho", fruto de trabalho honesto como advogado.

Até a divulgação da obra de Pagnan, a repercussão midiática atribuiu ao casal Nardoni um ethos negativo, ao vincular pai e madrasta a um crime contra uma criança de cinco anos de idade. Na concepção de Amossy (2010), a imagem discursiva pode servir tanto para reforçar uma imagem prévia quanto para transformá-la e entendemos que foi esse o ensejo da obra, transformar a imagem daqueles que passaram uma exposição negativa por muito tempo. Interpretamos que o interesse do jornalista foi transformar o ethos negativo do casal e as possíveis emoções negativas ligadas a ele. Ademais, interpretamos uma tentativa de questionar os rumores da investigação policial, seja desqualificando os profissionais da perícia ou apontando algumas lacunas no processo.

A estratégia deflagrada pelo jornalista foi a tentativa de construir, discursivamente, um ethos de tradição, o que, também, contribuiria para a credibilidade da família Nardoni, isto é, para que fosse vista como uma família de boa índole e respeitada pelas pessoas próximas com quem teve convívio. Para Charaudeau (2008, p. 211), o imaginário da tradição "é sustentado por discursos que se referem a um mundo longínquo no tempo, no qual os indivíduos teriam conhecido um estado de pureza. Esse mundo é evocado como um paraíso perdido (a idade de ouro da Antiguidade, o Éden da Bíblia) ao qual seria preciso voltar para reencontrar uma origem, fonte de autenticidade".

A obra busca resgatar não só a história do casal condenado, mas as imagens positivas ligadas à família dele desde o nascimento. Para tanto, não se prende à história propriamente dita, mas traz os depoimentos de vizinhos e conhecidos que corroboram 
a imagem de amizade, idoneidade, responsabilidade e empatia. A imagem da tradição aparece, também, na fala dos conhecidos, dando credibilidade às informações apresentadas durante a narrativa. A obra busca, para fundamentar o histórico de bons antecedentes, portanto, um retorno às origens identitárias e o reconhecimento dessa identidade e da imagem que o casal e suas famílias tinham frente à população.

Percebemos que o autor buscou distanciar da imagem negativa potencialmente gerada pelo crime e também apontar vários infortúnios que comprometerem a legítima defesa do casal, entre eles a condução dos trabalhos dos advogados de defesa que foi tumultuada com a desistência de alguns no caso, a exposição midiática do promotor responsável Francisco José Cembranelli que, para o jornalista, era "experiente e pouco modesto" (PAGNAN, 2018, p. 243). O ethos midiático do promotor foi reafirmado no julgamento dos réus, em que o autor considerou o acontecimento com grandes performances, considerando "a estrela do dia" a maquete do edifício London foi instalada no meio do plenário.

No capítulo "Quem matou Odete", o jornalista Pagnan remonta a história da vilã Odete Roitman, personagem vivida por Beatriz Segall na novela Vale Tudo. A menção à personagem deve-se ao suspense ao redor da trama que tentava desvendar o assassino ou assassina da personagem. O suspense de quem a teria matado rendeu picos de audiência à emissora Globo e foi essa analogia que o jornalista assinala no caso Nardoni, as notícias sensacionalistas em torno do fato, e o consequente clamor popular, que, de certa forma, atrapalharam o "verdadeiro" desfecho do crime.

Por fim, na tentativa de refazer suas imagens arranhadas pelo julgamento social segundo o qual o casal foi condenado como responsável pelo crime de uma menina de cinco, isto é, visando inverter o ethos prévio de "monstruosidade" e desumano erigido pela população, no livro, vemos a tentativa de criação do ethos de responsabilidade e humanidade de pessoas vítimas de uma injustiça da sociedade, dos órgãos públicos e das pessoas investidas na investigação e julgamento do caso.

A partir das imagens de injustiçados pelo julgamento prévio até mesmo de policiais que deveriam prestar um serviço pela isenção e imparcialidade, vemos a tentativa do jornalista em transformar as emoções negativas possivelmente sentidas pela sociedade diante de um crime hediondo e sem motivação aparente, em uma perspectiva positiva. Vale ressaltar que as emoções são engendradas por julgamentos de valor a respeito de algum assunto, fato ou atitude. Como verificamos, o casal se diz inocente todo o tempo mesmo quando a confissão poderia beneficiá-los com a diminuição da pena. O livro traz depoimentos de pessoas que expressam a tristeza pelo ocorrido e a confiança na inocência do casal, por meio do uso do léxico "comoção", emoção esta que poderia ser experimentada pelo leitor. Além da emoção, a dúvida quanto à autoria, de uma possível injustiça cometida pela justiça brasileira e uma possível reviravolta no caso. 
A atitude de indignação pode causar no leitor uma espécie de condolência aos dois seres humanos muito bem criados e que foram a eles imputados um crime injustamente. Para reforçar o descrédito na justiça, no final do livro, o autor descreve como está a vida de cada um dos familiares. Enquanto é atribuída uma imagem de que a mãe de Isabella está muito bem e feliz, casada e com filhos, a família do Alexandre está em busca de superação, de se reerguer e se desvencilhar das injustiças das pessoas. O pai Antônio Nardoni, por exemplo, ficou insatisfeito com o andamento do processo do filho e da nora e abandonou a carreira de advogado e hoje se dedica profissionalmente a outras áreas.

O leitor é instigado a perceber que há uma esperança pelos vários erros durante a investigação policial de que Alexandre Nardoni e Anna Carolina Jatobá são inocentes. Entendemos que, ao suscitar a esperança no auditório, possivelmente o casal, quando saísse da prisão, depois de cumprido a pena imposta, teria apoio e compaixão da sociedade.

O livro mostra as qualidades de Alexandre Nardoni e de sua família, mostrando quão são pessoas trabalhadoras, amáveis, donas de simplicidade e honestidade e, ainda, mostra a incredulidade dos vizinhos quanto à autoria do crime de Isabella. "São gente fina mesmo. Gente muito boa" (PAGNAN, 2018, p. 135), reproduz a fala de Dona Carmem, vizinha.

No final do livro, a voz da Cristiane, irmã de Alexandre, é evocada para confirmar a não autoria do crime por Alexandre, a esperança de encontrar o verdadeiro assassino é posta com uma frase de efeito: "Ele fala que vai viver para saber o que houve com Isabella. Ele não tira isso da cabeça dele. Oremos a Deus para que um dia a verdade venha à tona" (PAGNAN, 2018, p.332).

A sentença é construída a partir da afirmação da inocência de Alexandre Nardoni, que, assim, gera convicção de um clamor midiático e um erro judiciário em sua condenação e, de certa forma, "obriga" o leitor a aceitar o discurso como verdadeiro. Ao usar a fala da Cristiane, que diz que Alexandre tem certeza disso, o autor constrói um discurso que preza pela credibilidade, alicerçada na modalidade do saber.

Além da tentativa de construção da imagem de responsáveis e frutos de famílias de pais trabalhadores e que prezam pela simplicidade, existem outras estratégias argumentativas no livro que poderiam intensificar a esperança, engendrar o pathos, de modo a fazer o auditório aderir mais facilmente àquilo que é dito. No final da obra, o autor descreve uma família destruída, tentando recomeçar, de modo geral, trazendo, novamente, a esperança, a partir da ideia de recomeço e de um novo futuro.

A história contada sobre Alexandre Nardoni se assemelha a de muitos "heróis" biográficos do lado avesso ou "heróis" injustiçados, ou seja, a narrativa se desenvolve 
mostrando as dificuldades financeiras da família em sua infância, depois os subterfúgios para a superação dos obstáculos e, finalmente, na hora do alcance do sucesso, uma inconsistência policial e jurídica é um impeditivo para a glória. Inclusive, o nascimento de Alexandre foi narrado como um espetáculo e o peso e a altura minimamente especificados. Enfim, uma história de um predestinado, mas por um desvio no caminho, não teve sucesso como delegado de polícia, um sonho que não pode ser realizado. Podendo despertar no leitor, assim, um efeito patêmico de piedade.

Ao narrar a história de outrem, o autor recorre às lembranças de experiências e acontecimentos vividos e, assim, estrutura a vida e constrói as identidades pela sua atuação na sociedade e no relacionamento com os outros. Infere-se que o título da obra "O pior dos crimes" não apenas destaca a brutalidade do assassinato de Isabella, mas também a injustiça na condenação dos envolvidos.

\section{Considerações finais}

Examinada a composição da obra literária de Pagnan (2018) por meio da análise das estratégias discursivas e sua relação dialógica com os conceitos da Análise do Discurso, mais especificamente o ethos, interpretamos que a narrativa do jornalista foi construída como uma tentativa de melhorar a imagem do casal Nardoni, que mesmo não confessando o crime, foi condenado pelo homicídio da menina Isabella. Além do casal, os familiares vivenciaram impactos negativos em relação às suas imagens. Em meio a um momento em que os condenados receberam o benefício das saídas temporárias das prisões, sentimos que houve a necessidade de um posicionamento de uma pessoa "de fora", um profissional da mídia, que lida com a "verdade" e "imparcialidade" na rotina jornalística, para ressaltar as lacunas da investigação, as dúvidas com relação à autoria e mostrar um papel de pessoas idôneas diante da sociedade.

O casal recebeu o benefício da saída temporária de Dia dos Pais em 2019. A saída temporária está estabelecida entre os artigos 122 e 125 da Lei de Execução Penal (LEP), criada em 1984 para unificar a aplicação das punições a condenados no Brasil. Além de apresentarem bons comportamentos, Alexandre e Anna Carolina preenchem os requisitos: presos em regime semiaberto que já cumpriram 1/6 pena e são réus primários.

Percebemos que o jornalista delineou os perfis das pessoas das famílias do casal e do próprio casal, explorando não só o acontecimento, o crime em si, mas revelando marcas de subjetividade e atribuindo traços de caráter (ethos) a essas pessoas e até mesmo da mãe da Isabella, ao relatar crenças, valores, sentimentos e relações interpessoais dos envolvidos. Os acentos valorativos assumem representações para "quebrar" os imaginários cristalizados pela memória coletiva sobre o assassinato. Ao desconstruir os imaginários conhecidos pela população brasileira a respeito do pai e da 
madrasta de Isabella Nardoni, a narrativa sobre o casal é pautada no ordenamento de uma rotina de um ser comum, que comete erros e acertos na vida, tem decepções, mas, ao mesmo tempo, apresenta virtudes, uma imagem de bons seres humanos, pessoas generosas e benquistas.

A divulgação de uma obra que busca mostrar para o público "verdades" de um crime de comoção nacional, não exploradas pela mídia, é uma oportunidade para dar visibilidade às incongruências do processo criminal e mostrar as qualidades das pessoas que foram condenadas "injustamente", e ainda mostrar os seus sonhos e desejos não realizados e, com isso, conseguir transformar a imagem perante à sociedade: de "vilões", "monstros" para seres humanos com um histórico de vida com ações de muitas virtudes.

\section{Referências}

ARISTÓTELES. Retórica. Tradução: Manuel Alexandre Júnior, Paulo Farmhouse Alberto e Abel do Nascimento Pena. Lisboa: Imprensa Nacional - Casa da Moeda, 1998.

BARTHES, Roland. Introdução à análise estrutural da narrativa. In: BATHES, Roland et al. Análise estrutural da narrativa. Tradução: Maria Zélia Barbosa. Petrópolis: Rio de Janeiro, 2013. p. 19-62.

BERTAUX, Daniel. Le récit de vie. Paris: Armand Colin, 1994.

CARVALHO, Aline Torres Souza. Relações teórico-metodológicas entre a AD e a Narrativa de Vida. In: MACHADO, Ida Lúcia; MELO, Mônica Santos de Souza (orgs.). Estudos sobre narrativas em diferentes materialidades discursivas na visão da Análise do Discurso. Belo Horizonte: NAD; FALE; UFMG, 2016. p. 21-42.

CHARAUDEAU, Patrick. Uma análise semiolinguística do texto e do discurso. In: PAULIUKONIS, Maria Aparecida Lino; GAVAZZI, Sigrid (orgs.). Da língua ao discurso: reflexões para o ensino. Rio de Janeiro: Lucerna, 2005. p. 11-27.

CHARAUDEAU, Patrick. Discurso Político. 2. ed. Tradução: Fabiana Komesu e Dilson Ferreira da Cruz. São Paulo: Contexto, 2008.

DOSSE, François. O desafio biográfico: escrever uma vida. Tradução: Gilson César Cardoso de Souza. São Paulo: EdUSP, 2009.

GENETTE, Gérard. Fronteiras da narrativa. In: BATHES, Roland et al. Análise estrutural da narrativa. Tradução: Maria Zélia Barbosa. Petrópolis: Rio de janeiro, 2013. p. 265-284.

MACHADO, Ida Lúcia. Reflexões sobre uma corrente de análise do discurso e sua aplicação em narrativas de vida. Coimbra: Grácio Editor, 2016.

MAINGUENEAU, Dominique. A propósito do ethos. In: MOTTA, Ana Raquel; SALGADO, Luciana (orgs.). Ethos discursivo. São Paulo: Contexto, 2008. p. 11-29.

PAGNAN, Rogério. 0 pior dos crimes: a história do assassinato de Isabella Nardoni. 2.ed. Record, 2018. 